\title{
Monitoring volcanic ash in the atmosphere
}

Fernando Chouza, Juan Carlos Dworniczak, Lidia Otero, Juan Pallotta, Mario Proyetti, Eduardo Quel, Pablo Ristori, Nobuo Sugimoto, Osvaldo Vilar, and Elian Wolfram

A South American network of lidar and remote sensing instruments can be used to minimize disruption caused by volcanic eruptions.

On several occasions, volcanic eruptions in the Andes have disrupted airspace for prolonged periods. Such eruptions include those in the southern Andes at the Chaiten volcano on 6 May $2008,{ }^{1}$ and at Puyehue-Cordón Caulle on 4 June 2011. The 2011 eruption caused the suspension of about 3000 domestic flights over a period of seven months. Volcanic ash reached the city of Buenos Aires, which is $1700 \mathrm{~km}$ from the eruption site, a number of times and caused widespread interruptions to air travel at the Ministro Pistarini International Airport in Ezeiza, Buenos Aires Province. $^{2}$

The Argentinian authorities and the main affected airlines concluded that there is a need to monitor and model the concentration and spatial distribution of volcanic ashes produced by such eruptions, to assure safe flights through the disturbed areas. In addition, the current monitoring stations must feature modern instrumentation suites that are capable of characterizing these complex phenomena. Information concerning the vertical distribution of volcanic ash, for example, can be used to determine which altitudes to avoid during flights.

We have developed a monitoring network that includes at each of its nodes lidar (light detection and ranging) systems suitable for continuous remote sensing of volcanic ashes. We are also responsible for installing the instruments and training the local National Weather Service (NWS) staff at the different sites to operate the equipment and to provide the necessary information to the Volcanic Ash Advisory Center (VAAC). ${ }^{3}$ Funded by the Ministry of Defense, five lidar stations have now been constructed at the airports in Bariloche, Comodoro Rivadavia, Rio Gallegos, Trelew, and Ezeiza. Each station contains a lidar system that we have built, a sun photometer, a particle counter, a visible light-UV radiometer, and an automatic weather station with a soil temperature sensor. We anticipate that multi-axis

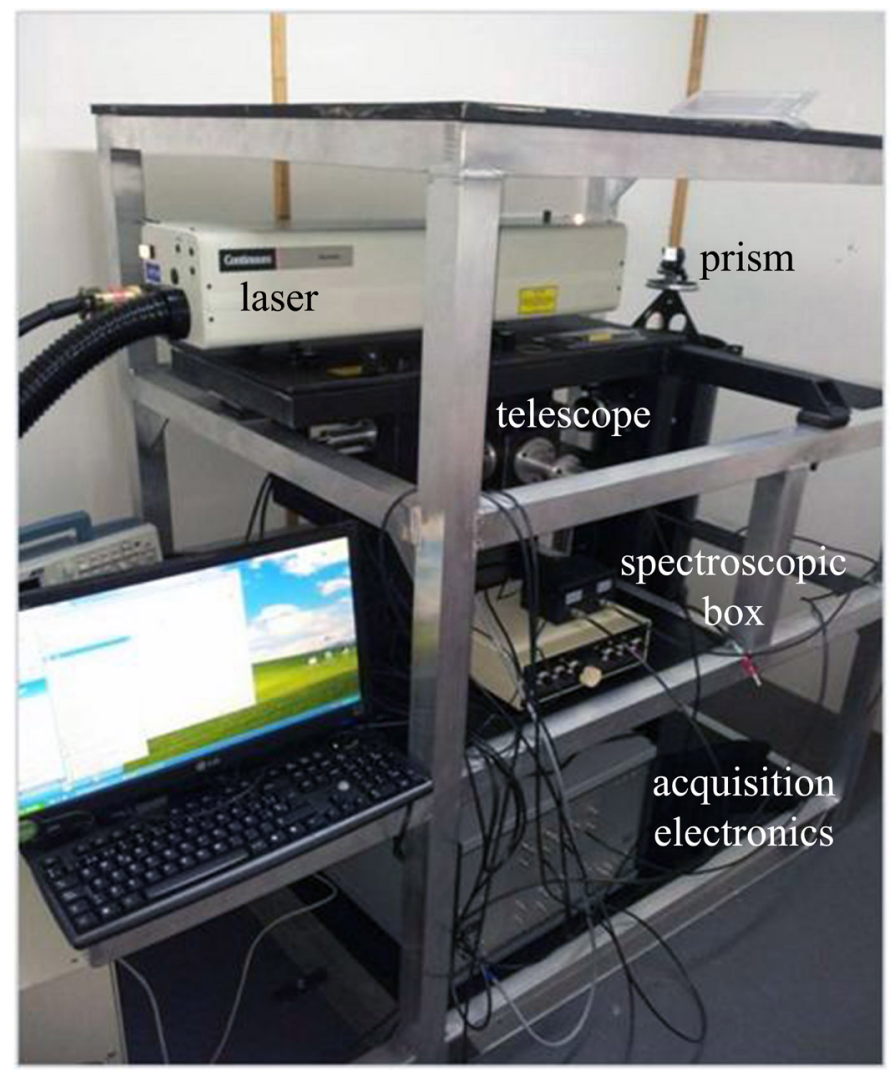

Figure 1. Prototype of the lidar system developed for volcanic ash monitoring stations. A laser head sends short infrared-visible light-UV pulses to the atmosphere through the small prism placed in front of it. Below the prism, a 1m-focal-length telescope receives and transmits the backscattered radiation to the spectroscopic box. The acquisition electronics and computer system acquires, processes, and stores the signal.

differential optical absorption spectroscopy (MAX-DOAS) instruments, full-sky cameras, and small radar systems will be added to the stations in the future.

Six new sun photometers are being installed and will be added to the system of four existing sites in Argentina (Villa Martelli, Rio Gallegos, Trelew, and the Casleo Observatory close to the

Continued on next page 
City of San Juan). These will operate as part of NASA's Aerosol Robotic Network (AERONET) to provide aerosol measurement data using the same instruments, as well as the same calibration and inversion procedures that are used to provide the worldwide data available via the AERONET website.

Our lidar systems (see Figure 1) use flash-lamp-pumped neodymium-doped yttrium aluminum garnet (Nd:YAG) lasers. A filter-based spectroscopic box measures the wavelength of the laser that has been backscattered off the target material (e.g., volcanic ash or aerosols). These may be at the Raman-shifted (inelastic scattering) wavelength of nitrogen in the UV and visible ranges, or at the Raman-shifted wavelength of water vapor in the UV. The measured light intensity and attenuation, as well as the depolarization (measured in the UV or visible channel) can be used to characterize the density, shape, and size of the volcanic ash particles.

The first station that uses our lidar instruments was installed and became operational on 1 February 2012 at Bariloche International Airport, which had been closed since the 2011 volcanic eruption. ${ }^{4-6}$ Since then, the instruments have been transmitting data that is processed by the NWS for reports to the VAAC and the Lidar Division at the Laser and Applications Research Center (CEILAP) of the Research Unit for Defense (UNIDEF). ${ }^{3,7}$ This station has been developed within the framework of a Japan International Cooperation Agency (JICA) program, as a prototype node for a future aerosol-monitoring lidar network in Japan. A second station, in Comodoro Rivadavia, began operations on 8 October 2012 as a volcanic aerosol sensing station. Both stations are operated by NWS and have not experienced any interruptions since their installation. Figure 2 and Figure 3 show signals from these stations. The second stage of our project, which involves installing the remaining stations, began on 1 March 2013 with the start of operations at Rio Gallegos International Airport.

In summary, we have developed a network of lidar and other remote sensing instruments to monitor volcanic ash clouds and

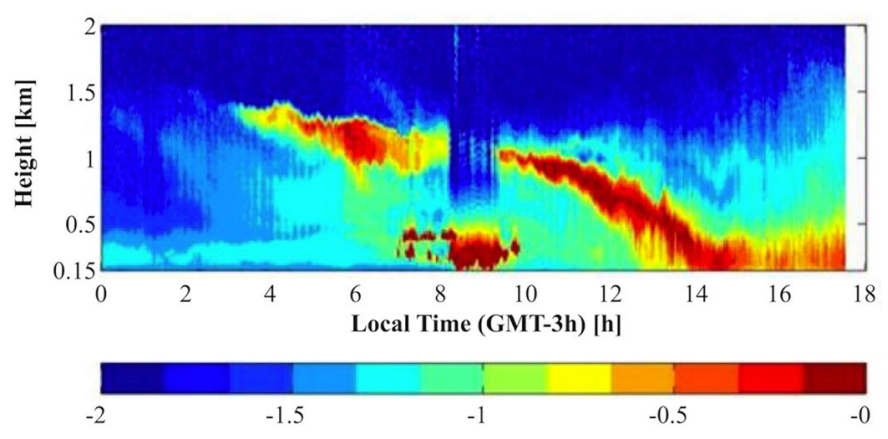

Figure 2. Range-corrected backscatter diagram, showing a volcanic ash deposition event on 23 February 2012.

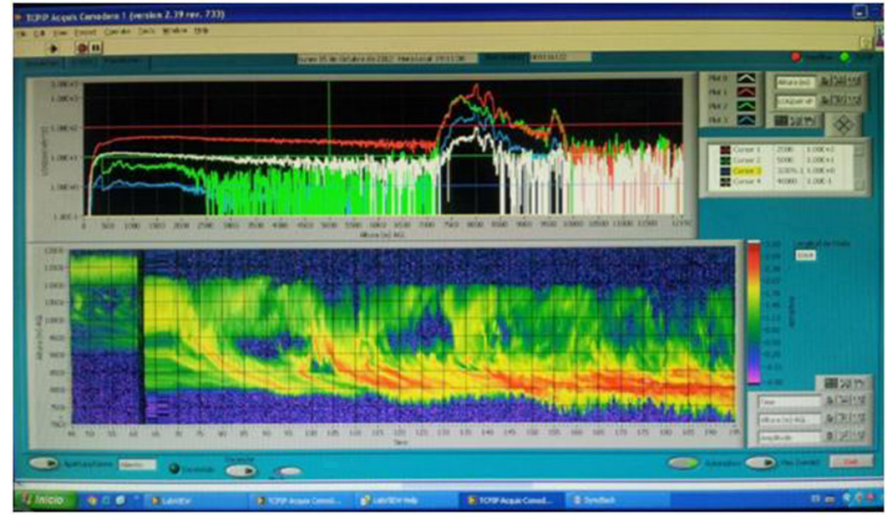

Figure 3. Screenshot of lidar acquisition software being used at the Rio Gallegos volcanic ash monitoring station, during its installation. The top plot shows range-corrected signals from the elastic lidar channels. The bottom section is a detailed color plot of a cirrus cloud observed at a wavelength of $1064 \mathrm{~nm}$.

to maintain air travel safety in Argentina. The network will be expanded further in a coordinated project that involves teams from the University of Magallanes in Punta Arenas, Chile, the Japanese Science and Technology Agency, and JICA. The main goal of this project is to develop an atmospheric environmental risk-management system in South America. This program will allow observations to be processed and modeled to assess and manage risks in real time. In addition, it will involve four new lidar systems, three of which will include high-spectral-resolution lidar instruments.

We would like to thank several individuals who have made important contributions to this project: Patricio Ballesteros, Daniela Bulnes, Gabriela Nicora, Facundo Orte, Marcelo Raponi, Jacobo Salvador, Evangelina Martorella, Andrea Pereyra, Raúl D'Elía, Marcelo Ferrari, Francisco González, and Ezequiel Pawelko at CEILAP; and Sebastián Masi, Carla Repetto, and Pablo Vasquez at the National Technological University in Buenos Aires.

\section{Author Information}

Fernando Chouza, Juan Carlos Dworniczak, Lidia Otero, Juan Pallotta, Mario Proyetti, Eduardo Quel, Pablo Ristori, Nobuo Sugimoto, Osvaldo Vilar, and Elian Wolfram Laser and Applications Research Center (CEILAP) CITEDEF-CONICET

Buenos Aires, Argentina 
References

1. E. E. Pawelko, P. R. Ristori, L. A. Otero, and E. J. Quel, Chaitén volcanic aerosol transport study during May 2008, Proc. 25th Int'1 Laser Radar Conf., pp. 215-218, 2010

2. L. Otero, P. Ristori, J. Pallotta, E. Pawelko, and E. Quel, The Puyehue-Cordón Caulle volcanic eruption, June 2011: Water vapor, atmospheric boundary layer and aerosol temporal evolution in Buenos Aires, Argentina, Revista Boliviana de Física 21, pp. 27-29, 2012.

3. http://www.smn.gov.ar/vaac/buenosaires/inicio.php Website for the Volcanic Ash Advisory Center in Buenos Aires. Accessed 30 May 2013.

4. P. Ristori, L. Otero, E. Pawelko, J. Pallotta, R. D'Elía, F. Chouza, F. González, et al., Development of an Argentinean lidar network to monitor the volcanic plume and dust in Patagonia, Proc. 26th Int'l Laser Radar Conf., pp. 357-360, 2012.

5. P. Ristori, L. Otero, J. Pallotta, E. Pawelko, and E. Quel, Biomass burning and volcanic ash characterization at Centre de Investigaciones en Láseres y Aplicaciones, Buenos Aires, Argentina, Revista Boliviana de Física 21, pp. 30-32, 2012.

6. E. Pawelko, P. Ristori, L. Otero, R. D'Elia, A. Pereyra, O. Vilar, F. Chouza, et al., Multiwavelength Raman lidar construction to monitor volcanic ash and aerosols in Bariloche International Airport, Proc. 26th Int'1 Laser Radar Conf., pp. 285-288, 2012.

7. http://division-lidar.com.ar Website for the Lidar Division at CEILAP. Accessed 30 May 2013 